\title{
História e cultura local na formação docente em Química ${ }^{1}$
}

Local History and culture in chemistry teacher training

Anelise Maria Regiani ${ }^{2}$

\section{Resumo}

Este artigo descreve trabalho desenvolvido em salas de aula da licenciatura em química e do ensino médio urbano e rural para o ensino de química em uma perspectiva intercultural. O estado do Acre (Brasil) foi constituído a partir da ocupação de território na Floresta Amazônica por interesses econômicos nos denominados "surtos da borracha". Planos de ensino e materiais didáticos foram escritos a partir do contexto histórico e social desta movimentação de pessoas e da aproximação do conhecimento de seringueiros e indígenas do conhecimento científico. As narrativas, experimentos e vivências foram propostos com base em trabalhos de campo, de laboratório e pesquisa bibliográfica. A dinâmica das atividades propostas oportunizou a formação de um docente mais humanista, bem como propiciou na escola média o aprendizado da ciência química e o reconhecimento do valor das populações da floresta pelos estudantes do centro urbano e o reconhecimento do próprio valor pelos estudantes da escola rural.

Palavras chave: conhecimento tradicional; perspectiva intercultural; escolas amazônicas; Acre.

\section{Abstract}

This article describes work developed in chemistry teaching training courses and in urban and rural high school classrooms in an intercultural perspective. The state of Acre (Brazil) was constituted from the occupation of territory in the Amazon Forest by economic interests in the so-called "rubber outbreaks". Teaching plans and materials were written considering the historical and social contexts of these episodes and the approximation of the knowledge of rubber tappers and of indigenous people to scientific knowledge. The narratives, experiments and experiences proposed were based on fieldwork, laboratory and bibliographic research. The dynamics of the materials used made possible, beyond the learning of the chemical science, the recognition of the value of the forest populations by the students of the urban center and the recognition of the own value by the rural school students.

Keywords: chemistry teaching; intercultural perspective; Amazonian schools; Acre.

\footnotetext{
${ }^{1}$ Versão de uma conferência apresentada durante o 15 Simpósio Brasileiro de Ensino de Química - SIMPEQUI, realizado de 7 a 9 de agosto de 2017 na cidade de Manaus, Brasil.

2 Universidade Federal de Santa Catarina | anelise.regiani@ufsc.br
} 


\section{O ensino de química em uma perspectiva humanista}

No senso comum da sociedade do século XXI, a ciência tem status de inquestionável. Atribui-se à ciência o poder de juízo de valor sobre o que é válido ou não. Este patamar a ela concedido, ou o carimbo de cientificamente comprovado, decorre de sua característica empírica: experimentos planejados sistematicamente e capazes de serem reproduzidos repetidas vezes sob as mesmas condições em qualquer lugar, conferindo sempre o mesmo resultado. A ciência construída a partir de um procedimento uniforme produziu inúmeras verdades. Com essa visão, a educação científica que se propõe simplifica a ciência a um conjunto de verdades experenciadas independentes de opinião, crença, valores e cultura. Esses dogmas são merecedores de memorização e os seus "descobridores", iluminados homens brancos e europeus, são celebrados. E assim, a ciência vem sendo ensinada nas escolas de uma forma asséptica (CHASSOT, 2011).

Feyerabend, em seu livro Contra o Método (2007), argumenta que "os eventos, os procedimentos e os resultados que constituem as ciências não têm uma estrutura comum" (p. 19) e que os cientistas, no desenvolvimento de suas teorias, abrem mão do método e usam aproximações não científicas. Nessa perspectiva, Feyerabend propõe que, na construção e no progresso da ciência, "tudo vale" (FEYERABEND, 2007, p.37) no sentido em que "não existe um método único de fazer ciência e os que existem podem ser melhorados com o intercâmbio de outras tradições" (DAMASIO e PEDUZZI, 2017, p.15). Souza (2013), ao apresentar resultados de pesquisa que analisa a etnofísica do manzuá ${ }^{3}$ produzido por ribeirinhos amazônicos com vistas ao desenvolvimento de materiais didáticos para o ensino de física nos níveis médio e superior, argumenta que o conhecimento físico tradicional dessa população e o conhecimento formal escolar não são antagônicos. Segundo o autor, esse conhecimento está relacionado a modelos mentais refinados ao longo dos anos de prática tradicional em que "conceitos-em-ação e teoremas-em-ação movimentados fazem parte desses modelos mentais" (SOUZA, 2013, p. 100).

Em uma educação científica humanista, o ensino de ciências contribui com a formação da consciência crítica, que faz do ser humano "um ser capaz de intervir no mundo e não só de a ele se adaptar" (FREIRE, 2005, p.20). Assim, a ciência é ensinada não como o único caminho para a verdade e a realidade, mas como uma visão de mundo que corrobora com a emancipação de um grupo social, Freire (2005) propõe o ensino pela abordagem temática onde o contexto do estudante é o ponto de partida para a educação escolar. No confronto entre o conhecimento empírico dos discentes e a cultura científica na análise de situaçõesproblema em estudo é possível a internalização pelo estudante dos conteúdos escolares. Para isso, é preciso que o docente de ciências perceba quais são os conhecimentos que a comunidade escolar possui e como esses saberes podem ser usados para estruturar oportunidades de aprendizagem em ciências. Desta forma, história e cultura também são conteúdos do ensino de química.

A história mostra que a conquista de "novos" mundos, atos de biopirataria, guerras globais e grande deslocamento de pessoas, dentre outros fatos, acontecem pela conquista e pelo domínio dos materiais. A história da ciência química e da economia são assim entrelaçadas evidenciando o caráter socioeconômico da química em que o conhecimento

\footnotetext{
${ }^{3}$ Manzuá é um artefato construído por ribeirinhos para ser utilizado na pesca.
} 
químico impulsiona e é impulsionado por transformações sociais (MACHADO, 2015). O mundo conhecido na antiguidade foi ampliado pela procura por compostos com propriedades únicas. No Brasil, a chegada dos colonizadores aconteceu em decorrência da busca por uma rota para o comércio das especiarias do Oriente. A ocupação das terras no além mar se deu, por exemplo, pela exploração do pau Brasil, pelas culturas da cana-deaçúcar e do café e pelos surtos do ouro e da borracha.

A região Amazônica, em especial, atraiu o olhar de estrangeiros

\begin{abstract}
ensandecidos pela cobiça descortinava-se também o horizonte natural e, nele, a vegetação abundante e pródiga em resinas, óleos, essências e todo tipo de secreção vegetal. Os exploradores, em contato com os saberes locais, depressa descobriram todo um universo de usos tradicionais desses materiais naturais e, imbuídos do espírito capitalista em expansão no mundo moderno, passaram a valorizá-los como fonte de "matérias-primas" com incontáveis aplicações industriais (MACHADO, 2015, p. 81).
\end{abstract}

As pessoas que trabalharam (e ainda trabalham) nessas atividades econômico-químicas agregaram a sua cultura e seus conhecimentos com vistas ao melhor resultado econômico e comercial para a nação. O trânsito de produtos entre os diferentes atores sociais produziram (e produzem), além de impactos locais e externos, desdobramentos cognitivos, políticos, econômicos, sociais e epistemológicos (MACHADO, 2015). Compreender porque esses materiais e atividades produtivas são especiais e como podem ser transformados e/ ou produzidos, além de (re)conhecer a cultura dos diversos grupos sociais e suas contribuições na formação do Brasil como nação, também deve ser assunto do conhecimento químico escolar.

\title{
Breve história do estado do Acre
}

O Acre é um estado que ocupa a porção sul-ocidental da Floresta Amazônica. Segundo dados do IBGE (2017), o conjunto de 22 municípios tem área igual a 164.122,280 $\mathrm{km}^{2}$ sendo habitado por cerca de 733 mil pessoas (IBGE, 2017). A bandeira que representa o estado foi instituída em 1995 adotando a do Estado Independente do Acre, república proclamada pelo espanhol Luiz Galvez em 1899. Ela traz as cores verde e amarela da bandeira brasileira e a estrela vermelha, a estrela altaneira tinta no sangue de heróis (MANGABEIRA, 1903). Este símbolo traz consigo a história de ocupação do território e a luta pelo reconhecimento de pertencimento.

Originalmente, a região, que competia, em 1880 ao Peru e à Bolívia, era ocupada por, pelo menos, 50 povos indígenas falantes de línguas Pano, Arawak e Arawá (SOUZA, 2002). No primeiro ciclo da borracha, seringais foram abertos e a borracha neles produzida era escoada por Manaus. O impasse econômico do pagamento de impostos gerou conflitos armados e a proclamação do estado independente em 1899. Entretanto, porque o Brasil reconhecia a soberania da Bolívia sobre o território, o presidente da república do Acre, Luiz Galvez, foi deposto, preso e deportado. Mas o desejo de pertencimento dos seringueiros e seringalistas e o interesse econômico do governo do Amazonas persistiam. Em 1902, com a formação de um exército de seringueiros e seringalistas sob o comando do militar Plácido de Castro, inicia a Revolução Acriana, finalizada em 1903 com a assinatura do Tratado de 
Petrópolis. O primeiro surto da borracha no Brasil finaliza com a implantação, pelos ingleses, dos seringais cultivados na Malásia a partir do desenvolvimento de sementes roubadas da Amazônia brasileira por Henry Wickham (JACKSON, 2011). Os seringais cultivados são mais produtivos com custo de produção menor do que os naturais porque neles as seringueiras estão próximas umas das outras, facilitando o corte das árvores e a coleta do látex.

A borracha de seringueira e o Acre voltam à cena por ocasião da Segunda Guerra Mundial. Com a entrada dos Estados Unidos no conflito após o bombardeio em Pearl Harbour e a ocupação dos seringais da Malásia pelos japoneses, os governos estadunidense e brasileiro assinam, em 1942, acordos de fornecimento de matérias primas estratégicas, dentre elas, a borracha. Assim, com o financiamento do governo dos Estados Unidos, cerca de 55 mil brasileiros nordestinos foram enviados para os fronts no interior da Floresta Amazônica, eram os soldados da borracha. Para o governo brasileiro o acordo era interessante porque o ajudava a "resolver" o problema da seca no Nordeste. Assim, para atrair o povo sofrido com a seca, o artista suíço Jean Pierre Chabloz foi contratado para confeccionar cartazes coloridos que mostravam seringueiros "recolhendo baldes de látex que escorria como água de grossas seringueiras (figura 1). Todo o caminho que levava do sertão nordestino, seco e amarelo, ao paraíso verde e úmido da Amazônia estava retratado naqueles cartazes repletos de palavras fortes e otimistas"(NEVES, 2004, p. 3).

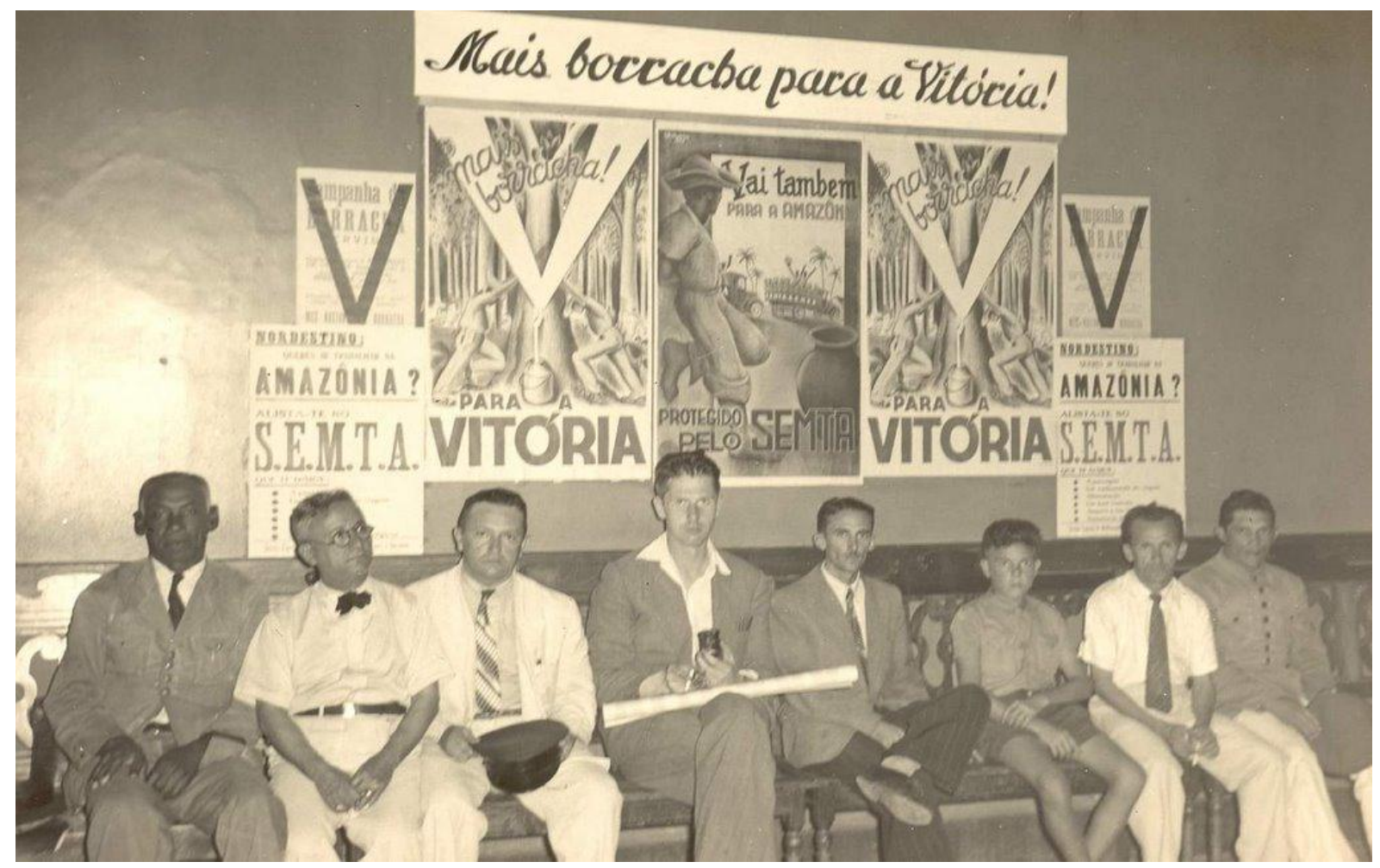

Figura 1: Imagens dos cartazes produzidos por Jean Pierre Chabloz para atrair brasileiros ao alistamento como soldados da borracha (MACHADO, 2005)

Novos seringais são instalados e o progresso chega novamente aos rincões da floresta. As negras pélas de borracha voltam a ser símbolo de riqueza (figuras 2). Com o término da guerra em 1945, o governo estadunidense encerra o acordo com o Brasil. Terminava o 
segundo surto da borracha. Metade do contingente da brigada florestal havia morrido e os sobreviventes não foram enviados de volta à terra natal; foram simplesmente esquecidos na Floresta.

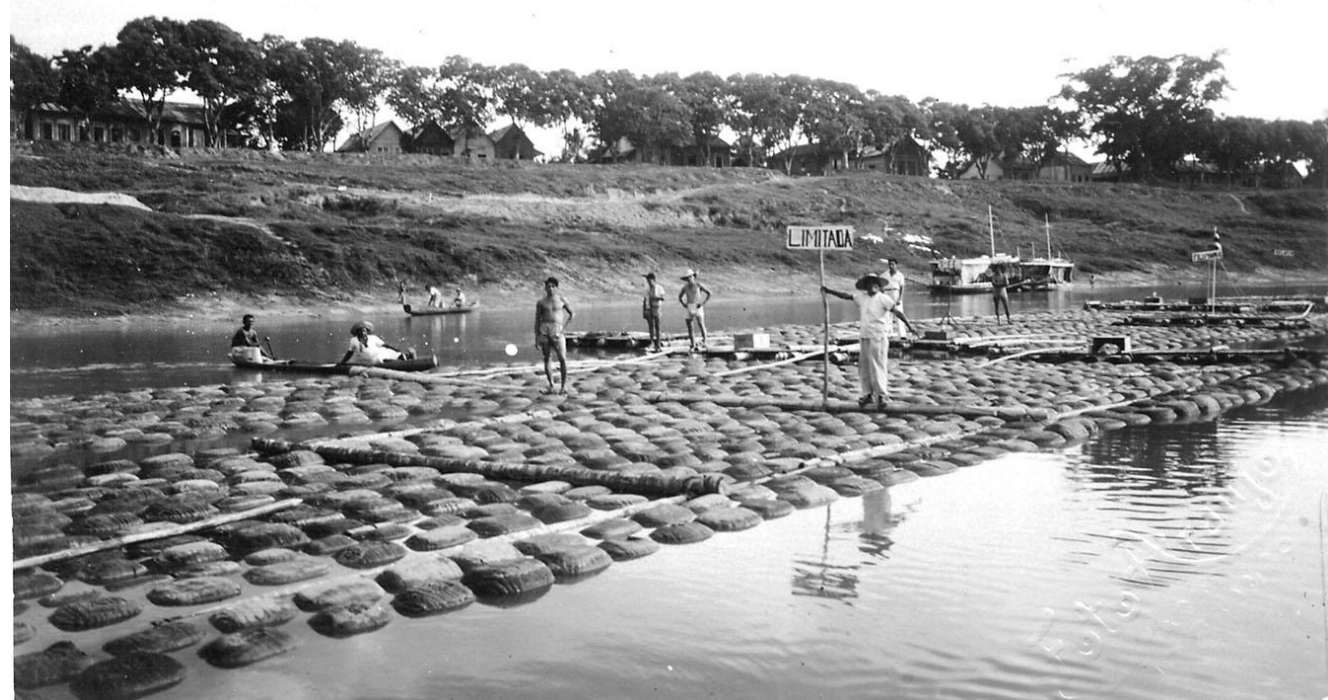

Figura 2: Pélas de borracha sendo transportadas no Rio Acre no município de Rio Branco (FOTO ARAÚJO, 1949)

Com a borracha malaia novamente no mercado, os seringais brasileiros entram em declínio. Em 1970 têm início movimentos antagônicos: o desmatamento, com a transformação da floresta em fazendas de gado por pecuaristas vindos de outros estados brasileiros, e a luta pela preservação da floresta e pela regularização fundiária, promovidos pelas populações remanescentes dos ciclos da borracha e pelos povos indígenas. Para dirimir os conflitos, nos anos 1990, foram então criados os Projetos de Assentamento Extrativistas (Pae), as Reservas Extrativistas (Resex) e as Terras Indígenas (TIs).

Novo olhar é lançado sobre a Amazônia com a chegada do século XXI. O advento da biotecnologia, a valorização da biodiversidade e o conceito de sustentabilidade ambiental agregam um novo valor à floresta e aos produtos florestais. Todo esse contexto histórico e o fazer cultural dos povos da floresta é significativo para a aprendizagem em ciências, em especial em química.

\section{Relatos de experiências desenvolvidas na licenciatura em Química da Universidade Federal do Acre}

Em um trabalho preliminar, Regiani e Marques (2012) investigaram se e como a formação recebida pelos estudantes de licenciatura em química da Universidade Federal do Acre, UFAC, permitiu a elaboração de projetos de ensino que considerassem os saberes populares e o contexto acriano nos processos de ensino e aprendizagem. Ao analisar os trabalhos de conclusão de curso (TCC) produzidos pelos licenciandos, perceberam que os estudantes reconhecem a função social da educação em química, as limitações do modelo de ensino tradicional e a importância da contextualização e da interdisciplinaridade. 
Entretanto, os projetos de ensino elaborados e desenvolvidos estavam ainda presos ao conteúdismo, à contextualização como exemplificação e à resolução de problemas exemplares em química. Os autores concluíram que esses aspectos presentes nos TCCs são reflexos da influência da formação dos docentes que atuam no curso de licenciatura; bacharéis e engenheiros.

Considerações sobre cultura e contexto no currículo da licenciatura em química da UFAC foi promovida com trabalho desenvolvido por Regiani e Di Deus (2013). Com o objetivo de valorizar o contexto regional e os saberes das sociedades tradicionais acrianas, os autores buscaram promover um diálogo integrador entre docentes de áreas aparentemente distintas, química e antropologia, durante a oferta de um componente curricular da licenciatura em questão: Tópicos em culturas e ensino de química. O plano de ensino desta cadeira foi elaborado em conjunto pelo docente por ela responsável, antropólogo, e por docente da área de química de forma que os conteúdos de antropologia pudessem auxiliar os estudantes a considerar a cultura e o contexto local em seus projetos de ensino. Assim, o curso foi estruturado em três unidades temáticas: conceitos e temáticas antropológicas fundamentais; diversidade cultural no Acre e antropologia do conhecimento. Para elaborarem seus planos de aula, os estudantes foram encorajados a buscar contato direto com as lideranças tradicionais que residiam ou circulavam por Rio Branco. Ao analisar os textos dos futuros docentes, Regiani e Di Deus (2013) perceberam que os estudantes desenvolveram interesse em compreender como a química dialoga com outros sistemas de saber e em aplicar esse diálogo em suas vivências pedagógicas. Mas também foi verificado que as narrativas não apresentaram a problematização do conhecimento tradicional buscando compreendê-lo em seus próprios termos (perspectiva êmica) nem os relacionavam com a cultura científica desenvolvida pela química (perspectiva ética). Ou seja, estavam presentes nos trabalhos conceitos da antropologia e da química e um sinal de início de dialogicidade, mas ainda se verificava que contexto tradicional e químico estavam desconectados. Os autores atribuíram tal fato à ausência do professor formador em química nos momentos de discussão em sala de aula. Como a aproximação dos docentes de química e de antropologia aconteceu em discussões fora da sala de aula, a aproximação entre as áreas não foi explícita e vivenciada diretamente pelos estudantes da licenciatura. Esta constatação e suas implicações foram objetos de uma segunda proposta.

Para que os licenciandos do curso de química da UFAC pudessem vivenciar práticas e instrumentos formativos que permitissem uma abordagem intercultural dos conhecimentos em química em seus projetos de ensino, docentes das áreas de antropologia e química prepararam e ministraram em conjunto os componentes curriculares Tópicos em culturas e ensino de química e Instrumentação do ensino de química IV (do currículo da licenciatura em química da UFAC). No primeiro componente buscou-se valorizar os contextos regionais e os saberes de sociedades tradicionais por meio da discussão dos conceitos de cultura e etnocentrismo. No segundo, procurou-se que os licenciandos percebessem os saberes tradicionais como possível origem dos saberes científicos e considerassem a presença do conhecimento tradicional na sociedade urbana atual. Foi proposto que os estudantes se apropriassem das ferramentas de coleta de dados da antropologia para buscar o conhecimento popular e compreendê-lo de forma êmica, dos conhecimentos em química para compreender o tradicional de forma ética e das ferramentas de análise e construção textual da educação para a construção de narrativas híbridas (PINHEIRO e GIORDAN, 2010). 
As narrativas, experimentos e vivências foram propostas com base em trabalhos de campo, de laboratório e pesquisa bibliográfica. A dinâmica de desenvolvimento desse trabalho foi relatada por Anastácio e Regiani (2014).

A análise dos textos produzidos pelos estudantes mostrou que a metodologia oportunizou a eles o entrelaçamento das experiências cotidianas das sociedades acrianas com os conteúdos de química. A atividade possibilitou a mudança de atitude deles diante dos temas trabalhados de um quadro de relativo desinteresse inicial pelos conceitos e temáticas antropológicas para um grande empenho na pesquisa de temas de Química aplicados a realidades culturais específicas da região.

Tabela 1: Temas estudados pelos discentes do curso de licenciatura em química da UFAC relacionando conhecimentos tradicionais e Química.

\begin{tabular}{|c|c|}
\hline Ano & Tema do trabalho \\
\hline \multirow{5}{*}{2013} & Pinturas corporais indígenas com urucum (Bixa orellana) \\
\hline & Pinturas corporais indígenas com jenipapo (Genipa americana) \\
\hline & Produção de derivados de mandioca (Manihot esculenta Crantz): caiçuma \\
\hline & Produção de derivados de mandioca (Manihot esculenta Crantz): Tacacá \\
\hline & História, cultura e bioquímica da Ayahuasca \\
\hline \multirow{8}{*}{2014} & Cultivo e processamento do café a partir de relato de migrante \\
\hline & Extração e processamento do látex \\
\hline & Produção de licor e aluá de abacaxi \\
\hline & Sabonetes artesanais \\
\hline & Xarope de romã \\
\hline & Bolo pé de moleque \\
\hline & Uso de tingui e timbó \\
\hline & Produção de queijo \\
\hline \multirow{6}{*}{2015} & Marchetaria \\
\hline & Gengibirra \\
\hline & Carvão vegetal \\
\hline & Lambedor (xarope) de plantas medicinais \\
\hline & Rapé \\
\hline & Produção de molhos à base de tucupi \\
\hline
\end{tabular}

Essa formação com diálogo antropologia/ química foi desenvolvida ainda mais uma vez. Os trabalhos apresentados nas segunda e terceira edições da metodologia foram considerados tão interessantes que os discentes foram convidados a transforma-los em 
capítulos para a publicação do livro "Conhecimento tradicional e química: possíveis aproximações" (REGIANI, 2014). Alguns estudantes aprofundaram a experiência, oportunizando a realização de trabalhos de campo para a aplicação dos planos de aula, fortalecendo o diálogo com as sociedades tradicionais. Os resultados das continuações foram apresentados como trabalhos de conclusão de curso e como artigo científico (SILVA et al, 2016). A tabela 1 apresenta alguns temas estudados pelos discentes.

\title{
Relatos de experiências desenvolvidas em cursos de mestrado profissional em ensino de ciências
}

O mestrado profissional é uma modalidade de pós-graduação stricto sensu regulamentada pela portaria normativa número 17 de 28 de novembro de 2009 do Ministério da Educação. O objetivo desses cursos é a capacitação de profissionais mediante o estudo de técnicas, processos ou temáticas que atendam demanda do mercado de trabalho. Para a área de ensino, a Capes indica que

\begin{abstract}
Seu foco está na aplicação do conhecimento, ou seja, na pesquisa aplicada e no desenvolvimento de produtos e processos educacionais que sejam implementados em condições reais de ensino. [...] Destinam-se principalmente a professores da educação básica e/ou profissionais de ensino formal ou não formal nos diferentes campos de conhecimento, bem como a profissionais atuantes no ensino em saúde, educação profissional e tecnológica ou qualquer outra temática que caracterize as profissões contemporâneas. (CAPES, 2016, p. 14)
\end{abstract}

Nos programas de mestrado profissional em ensino de ciências na Universidade Estadual de Roraima (UERR) e na UFAC foram desenvolvidas três dissertações que envolveram a aproximação dos saberes tradicionais de comunidades de seringueiros acrianos (ANASTÁCIO, 2015; NÓBREGA, 2016; SANTOS, 2017).

Anastácio (2015) desenvolveu dissertação em que buscou relacionar a história da borracha ao estudo de polímeros. Para tal, a autora realizou intervenção pedagógica em uma escola de ensino médio no município de Rio Branco tendo em vista compreender como os saberes tradicionais dos seringueiros no contexto da história da borracha podem ser feitos saberes escolares. Para desenvolvimento da ação, a autora realizou pesquisas bibliográficas e estudo dos espaços não formais Parque Capitão Ciríaco, em Rio Branco, e Fábrica de Preservativos Masculinos Natex, em Xapuri. Estes espaços foram estudados mediante visitas aos locais e entrevistas com dirigentes e trabalhadores para entender como foram constituídos e os produtos oferecidos. O plano de ensino desenvolvido foi editado como produto educacional de sua dissertação (figura 3). Ele apresenta as estratégias e os recursos utilizados e desenvolvidos em uma metodologia de pesquisa-ação. O plano foi dividido em 6 atividades: (i) resgate histórico do Acre, com a problematização,a partir de vídeos disponíveis na internet, da história de ocupação da região mediante os surtos da borracha; (ii) aulas expositivas e dialogadas sobre a química de polímeros; (iii) visita ao espaço não formal Capitão Ciríaco, local em que os estudantes tiveram a oportunidade de cortar a seringueira (Hevea brasiliensis), coletar látex e observar o processo de defumação da borracha enquanto ouviam histórias de um ex-seringueiro; (iv) atividade experimental de síntese de geleca com cola branca e bórax; (v) visita à fábrica de preservativos masculinos; e 
(vi) apresentação dos grupos de estudantes sobre as visitas aos espaços e a relação entre eles e o conhecimento em química. Após análise dos dados coletados na execução do plano de ensino, Anastácio (2015) concluiu que "os estudantes do ensino médio puderam construir relações e significados mais complexos acerca dos conhecimentos químicos, ao mesmo tempo em que compreenderam a cultura local" (p. 70). A autora também ressaltou que os estudantes puderam "perceber a importância da construção do próprio conhecimento com base nos seus saberes e na sua realidade vivida, despertando um novo olhar para si mesmo e sobre os outros e, principalmente, sobre a relação social" (p.70).
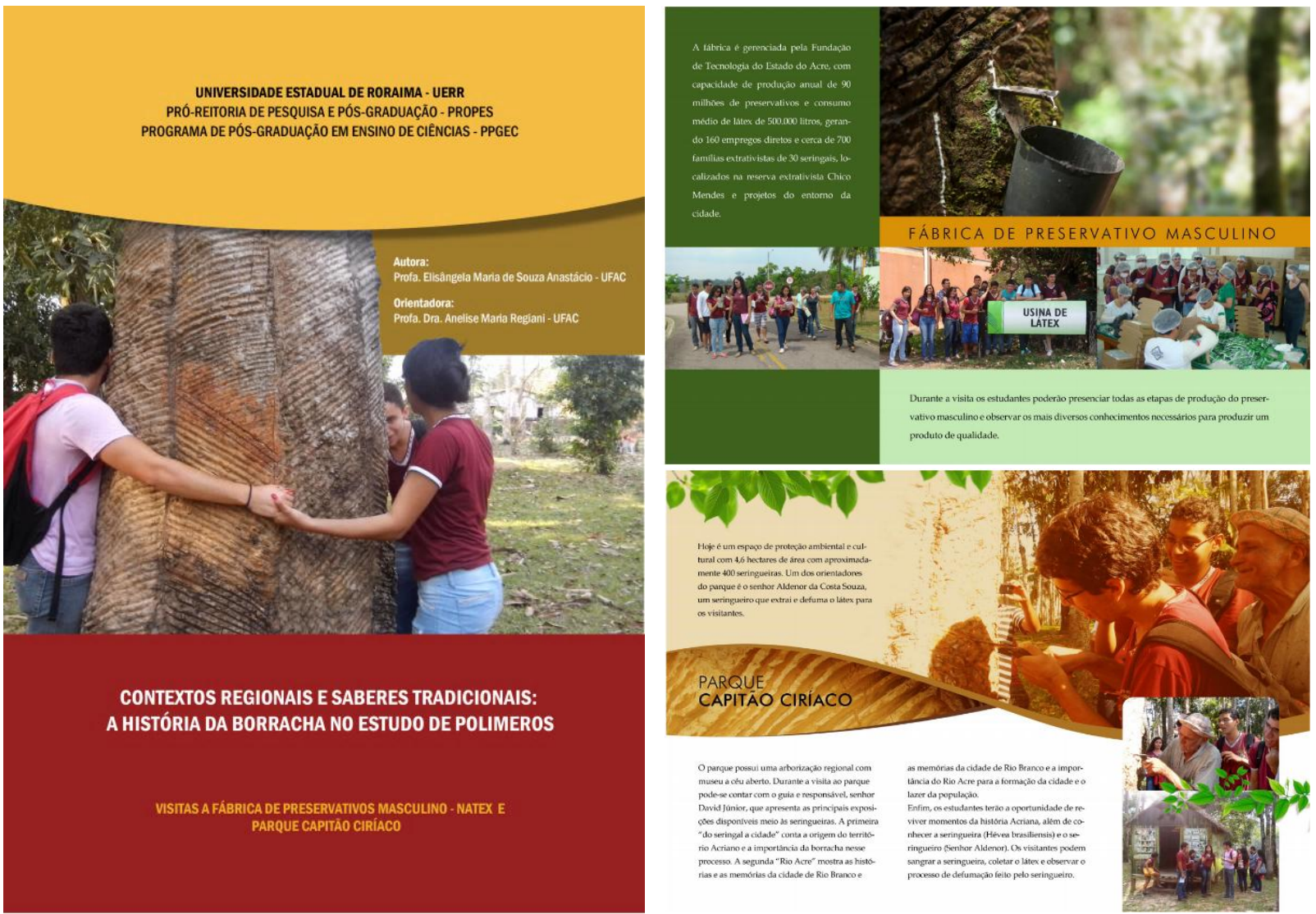

Figura 3: Imagens do produto educacional sobre ensino de polímeros no contexto da história da borracha produzido por Anastáscio (2015)

Nóbrega (2016) e Santos (2017) desenvolveram dissertações em que buscaram relacionar a história da borracha e o contexto dos seringais ao estudo de química e de biologia em escola rural na Comunidade Rio Branco, no Seringal Floresta da Resex Chico Mendes. Partindo de pesquisa qualitativa de cunho etnográfico, na qual realizou inventário das práticas de extração e processamento do látex com seringueiros do local, Nóbrega (2016) elaborou e desenvolveu plano de ensino que permitisse aproximar os conhecimentos tradicionais ao conhecimento científico em química. Assim, ao debruçar sobre a narrativa híbrida construída em sua vivência no seringal e na universidade, a autora apresenta em seu produto educacional (figura 4) uma estratégia de ensino com três momentos: (i) conhecendo nosso lugar, (ii) as transformações químicas no seringal e (iii) percorrendo as estradas de seringa. Partindo de músicas escritas por seringueiros, vídeos sobre história dos surtos da borracha e dinâmicas com fotos e exposições, a atividade de coleta e 
processamento de látex é problematizada. No desenvolvimento desta etapa, os estudantes puderam se (re)conhecer como autores da história mundial, resgatando a autoestima e o autovalor. O conteúdo em química é então abordado na segunda etapa por meio de aulas expositivas dialogadas e práticas experimentais. O último momento é uma atividade de avaliação da aprendizagem e revisão dos conteúdos. Para tal, foi desenvolvido um jogo de tabuleiro que retrata uma estrada de seringa. Ao percorrer as casas para coleta da cumbuca de latex, os jogadores vão respondendo perguntas sobre o conteúdo estudado. Nóbrega (2016) relata que, no decorrer do desenvolvimento da pesquisa, "os estudantes ficaram surpresos ao perceberem que o saber científico se faz presente nas ações executadas rotineiramente no seringal" (p.102). A autora concluiu que, quando as atividades do seringal são reinterpretadas junto aos componentes curriculares, o aprendizado de química torna-se mais efetivo e prazeroso.

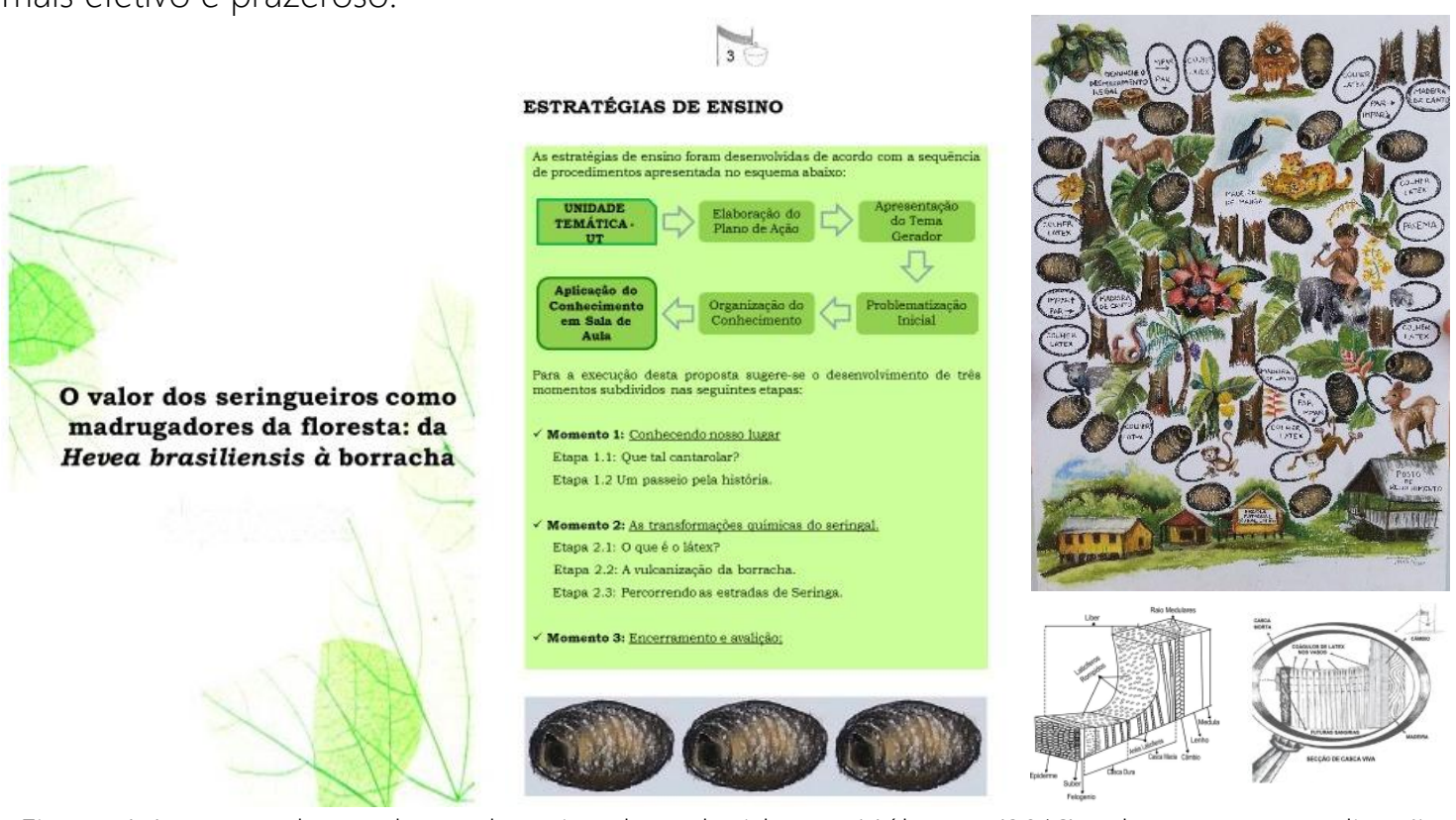

Figura 4: Imagens do produto educacional produzido por Nóbrega (2016) sobre a contextualização do ensino de química pela história da borracha.

Sobre o ensino de morfologia da folha, conteúdo de biologia vegetal, considerando os saberes e o contexto do seringal, Santos (2017) desenvolveu dissertação que buscou "valorizar o conhecimento tradicional da comunidade Rio Branco ao oportunizar fazer ciências a partir da relação desta população com as plantas" (p. 6). No contato com seringueiros em sua pesquisa de cunho etnográfico conheceu a relação deles com as plantas, identificação, modos de coleta e usos. Partindo dessa relação e do intuito de ensinar o ser e o fazer de um biólogo desenvolveu seu produto educacional. Segundo a autora,

O produto educacional elaborado trata-se de um plano de ensino dividido em etapas contemplando conteúdos de biologia vegetal, desde a importância das plantas para os seres vivos em geral como também a morfolologia e fisiologia das folhas. O material pedagógico foi dividido em momentos de ensino e aprendizagem, com dinâmica participativa, leituras de textos, ilustrações, demonstrações de materiais científicos, atividades práticas, confecção de desenhos, apresentações em grupos e socialização 
de conhecimentos por meio de rodas de conversas. Além disso, o plano de ensino apresenta sugestões de conteúdos de biologia vegetal que poderão ser abordados, com auxílio de equipamentos e materiais didáticos, como filmes, livros, catálogos, sites, entre outros que poderão ser utilizados pelo professor, oferecendo-Ihe oportunidade de criar novas situações de aprendizagem que contribua com ensino de qualidade voltado ao contexto sociocultural dos estudantes. (SANTOS, 2017, p. 56)

Santos (2017) relatou que, durante a execução das atividades, os estudantes informaram que haviam trabalhado com pesquisadores na coleta de material botânico, mas não tinham conhecimento sobre os resultados das pesquisas e o que faziam com o material coletado. A autora destaca a importância do pesquisador retribuir o trabalho da comunidade quando o recebe, o acolhe e o ajuda, retornando e mostrando o resultado de sua pesquisa. Ao realizar as coletas, preparar as exsicatas e desenhar as ilustrações botânicas, os estudantes perceberam os instrumentos e métodos da pesquisa em biologia e desenvolveram um novo olhar para a floresta em que estão inseridos. Ao final das aulas, os discentes mostraram, em suas narrativas, novas atitudes de preservação ambiental, amor e dedicação ao espaço em que vivem. Imagens do produto educacional confeccionado podem ser visualizadas na figura 5.
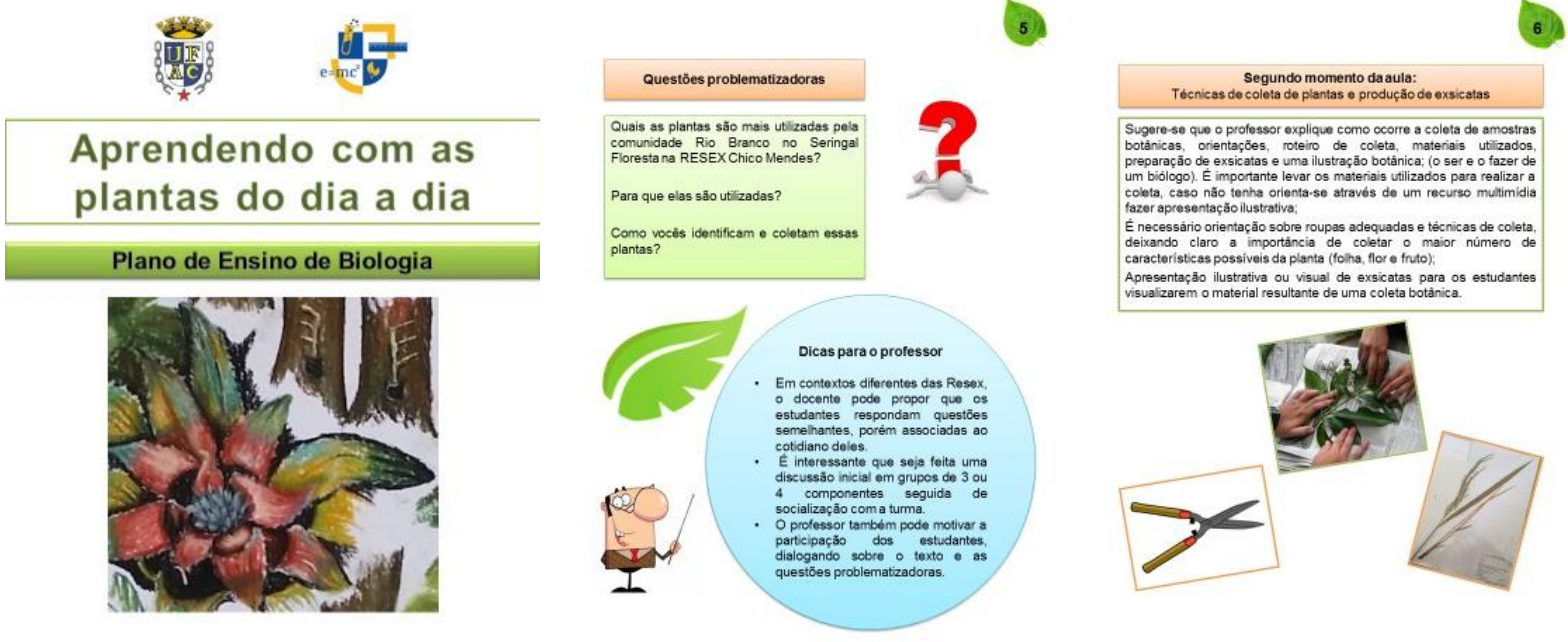

Figura 5: Imagens do produto educacional sobre morfologia da folha no contexto do seringal produzido por Santos (2017).

\section{Algumas considerações}

No decorrer do desenvolvimento de todos os trabalhos mencionados neste texto, foi possível perceber que a valorização dos contextos e das culturas regionais permite a docentes e discentes reconhecer as diferentes visões de mundo de diversos povos, além de valorizá-las e respeitá-las pelas suas contribuições à cultura global. Também é possível inferir que partindo do conhecimento e do contexto local o ensino e a aprendizagem de química e de ciências são mais significativos.

Entretanto, este não é um percurso isento de dificuldades. Na formação inicial há o entrave do convencimento dos formadores de docentes para o desenvolvimento de 
trabalhos conjuntos. Isso acontece por inúmeros motivos, desde a existência de possíveis vaidades e egoísmos de área até à demanda de tempo para planejamento e execução em conjunto.

Na educação básica o tempo também se configura em entrave. A preparação de materiais didáticos e narrativas que valorizem o conhecimento popular, além de tempo, demanda recursos humanos e financeiros. Seria interessante que o trabalho em parceria universidade-escola pudesse acontecer para além das iniciativas de projetos de mestrado profissional. A universidade com seu papel de formadora e produtora de conhecimentos poderia, junto com o docente da escola média, trabalhar na confecção de materiais, planos e projetos de ensino a serem estudados, avaliados, reestruturados e melhorados mediante as práticas docentes. Neste ir e vir, a educação escolar em ciências ganharia mais oportunidades de efetivar-se como humanista na formação de cidadãos conscientes de seu papel na sociedade, seja ela urbana ou rural.

\section{Referências}

ANASTÁCIO, Elisângela Maria de Souza. O ensino de polímeros no contexto da história da borracha no Acre.2015. 98p. Dissertação (Mestrado Profissional em Ensino de Ciências). Universidade Estadual de Roraima. Boa Vista.

ANASTÁCIO, Elisângela Maria de Souza; REGIANI, Anelise Maria. Conhecimentos tradicionais na formação dos professores de química. IN: REGIANI, Anelise Maria (Org). Conhecimento tradicional e química: possíveis aproximações. Curitiba: CRV, 2014.

CAPES. Coordenação de Aperfeiçoamento do Ensino. Ministério da Educação. Requisitos para a apresentação de propostas de cursos novos (APCN): Ensino. 2016. Disponível em http://capes.gov.br/images/documentos/Criterios_apcn_2semestre/Critérios_de_APCN_2017__Ensino.pdf. Acesso em: 30 jan 2018.

CHASSOT, Attico. Alfabetização científica: questões e desafios para a educação. 5 ed. ljuí: Unijuí, 2011

DAMASIO, Felipe; PEDUZZI, Luiz O. Q. Considerações sobre a alcunha atribuída a Paul Feyerabend de "pior inimigo da ciência" e suas implicações para o ensino de ciências. Alexandria, v. 10, n. 1, p. 329-351, 2017.

FEYERABEND, Paul Karl.Contra o método. Trad. Cezar Augusto Mortari. São Paulo: UNESP, 2007.

FOTO ARAÚJO. Rio Acre: [vista panorâmica da cidade]: Rio Branco, AC. IN: IBGE, Instituto Brasileiro de Geografia e Estatística. Disponível em https://biblioteca.ibge.gov.br/visualizacao/fotografias/GEBIS\%20-\%20RJ/0990.jpg. Acesso em: 18 set. 2017.

FREIRE, Paulo. Pedagogia do Oprimido. 49ed. Rio de Janeiro: Paz e Terra, 2005.

IBGE. Instituto Brasileiro de Geografia e Estatística. Disponível em https://cidades.ibge.gov.br/ v4/brasil/ac/panorama. Acesso em: 17 set 2017. 
JACKSON, Joe. O ladrão do fim do mundo: como um inglês roubou 70 mil sementes de seringueira e acabou com o monopólio do Brasil sobre a borracha. Rio de Janeiro: Objetiva, 2011.

MACHADO, Altino. Blog do Altino Machado. 2005. Disponível em http://www.altinomachado.com.br/2005/. Acesso em: 18 set. 2017.

MACHADO, Jorge Ricardo Coutinho. Natureza e Cultura entrelaçadas: o Boletim científico da Escola de Chimica Industrial do Pará. Amazônia: Revista de Educação em Ciências e Matemática, v.11, n. 22, p.61-78, 2015.

MANGABEIRA, Francisco. Hino do Acre. 1903. Disponível emhttps://pt.wikipedia.org/wiki/ Hino_do_Acre. Acesso em: 17 set. 2017.

NEVES, Marcos Vinícius. A heroica e desprezada batalha da borracha. História viva, v. 8. 2004.

NÓBREGA, Danielly de Souza. O contexto da história da borracha nos seringais acrianos: contribuições para o ensino de química. 2016. 109p. Dissertação (Mestrado Profissional em Ensino de Ciências e Matemática). Universidade Federal do Acre. Rio Branco.

PINHEIRO, Paulo Cesar; GIORDAN, Marcelo. O preparo do sabão de cinzas em Minas Gerais, Brasil: do status de etnociência à sua mediação para a sala de aula utilizando um sistema de hipermídia etnográfico. Investigações em Ensino de Ciências, v. 15, n. 2, p. 355383, 2010.

REGIANI, Anelise Maria. (Org) Conhecimento tradicional e química: possíveis aproximações. Curitiba: CRV, 2014.

REGIANI, Anelise Maria; DI DEUS, Eduardo. A cultura na química e a química na cultura: contextualizando o ensino de ciências na Amazônia acriana. Enseñanza de las Ciencias, v. 31, p. 2963-2966, 2013.

REGIANI, Anelise Maria; MARQUES, Carlos Alberto. O Contexto Amazônico na produção acadêmica de licenciandos em Química da Universidade Federal do Acre: revelações de um percurso formativo. Química Nova na Escola, v. 34, p. 67-74, 2012.

SANTOS, Lívia Fernandes dos. Ensinando biologia vegetal a partir do conhecimento tradicional de seringueiros do Seringal Floresta da Resex Chico Mendes. 2017. 81p. Dissertação (Mestrado Profissional em Ensino de Ciências e Matemática). Universidade Federal do Acre. Rio Branco.

SILVA, Maria Antônia Moura da; FALCÃO, Alcindo da Silva; SILVA, Marina Santana da; REGIANI, Anelise Maria. Tecelagem HuniKuin e o ensino de química. Química Nova na Escola, v. 38, n. 3, p. 200-207, 2016.

SOUZA, Carlos Alberto Alves de.História do Acre: novos temas, nova abordagem. 7 ed. Rio Branco: Envira, 2002.

SOUZA, Ednilson Sergio Ramalho de. Etnofísica, modelagem matemática, geometria... tudo no mesmo Manzuá. Amazônia: Revista de Educação em Ciências e Matemática, v.9,n.18, p.99-112, 2013. 